PUBLIC HEALTH PAST AND PRESENT

\title{
The pioneering use of a questionnaire to investigate a food borne disease outbreak in early 20th century Britain
}

\author{
Alfredo Morabia, Anne Hardy
}

J Epidemiol Community Health 2005;59:94-99. doi: 10.1136/jech.2004.025700

This paper describes the investigation by a British local government board inspector in 1902, H Timbrell Bulstrode, into the cause of an outbreak of enteric fever after a mayoral banquet given at Winchester. This investigation helped to confirm the role of oysters as an agent of transmission of typhoid fever. The data are also reanalysed using a modern approach, which confirmed the role of oysters (odds ratio $=11.2,95 \% \mathrm{Cl} 2.5$ to 50.1 ). This episode is illustrative of the role of British public health inspectors at the turn of the 20th century as well as of the conditions in which the technique of investigating outbreaks of food borne diseases using a standardised menu was developed. Current methods of outbreak investigations that differ from Bulstrode's pioneering work are also discussed.

See end of article for authors' affiliations

Correspondence to: Professor A Morabia, Division of Clinical Epidemiology, Geneva University Hospitals, 25 rue Micheli-du-Crest, 1211 Geneva 14, Switzerland; Alfredo.Morabia@ houge.ch

Accepted for publication 4 October 2004
$\mathrm{T}$ he investigation of outbreaks of food borne disease is an integral part of basic epidemiological training (http://www.phppo.cdc. gov/PHTN/catalog/pdf-file/Epi_Intro_l.pdf). The 1940 outbreak of staphylococcal gastroenteritis in the small village of Lycoming, in Oswego County, New York, may be the first example of a real outbreak that was transformed into a teaching exercise. After a church supper, most of the participants became ill with gastroenteritis. District health officers obtained food and illness histories from the 75 participants. Food specific attack rates, that is, the percentage of the participants who got sick, were very similar among the persons who ate and among those that did not eat specific foods, except for one item: the attack rate was $80 \%$ for those who had vanilla ice cream compared with $14 \%$ for those who did not have it. Bacteriological cultures showed that the agent was Staphylococcus aureus. It was later discovered that the bacteria may have been discharged from an external lesion on the hand of the maker of the ice cream. ${ }^{1}$ This example was used for more than 60 years throughout the United States and several other countries: used at Albany Medical College (1940), at the US Navy Epidemiology Training Program in Bethesda (1942), at The Johns Hopkins School of Hygiene and Public Health (1946), at the Centers for Disease Control in Atlanta (1949), in the Epidemic Intelligence Service training course (1951) and, it is included as an exercise entitled "Oswego, an outbreak investigation" in the software Epi Info 2000 (version 1.1.2-November 2001) (downloadable from the CDC http://www.cdc.gov/epiinfo/).

In the "Oswego Problem", vanilla ice cream was the only candidate found by the diet history. More recent examples of training exercises deal with more complex situations in which several items come out as potential causes of the outbreak. $^{2}$ In August 1974, an outbreak of streptococcal pharyngitis (sore throat) affected about 325 of 690 jail inmates in Miami, Florida. A questionnaire about the food items eaten was filled by a random sample of 314 inmates. Food specific attack rates were computed that showed that those who had eaten egg salad and a beverage at the noon meal of 16 August were more likely to have developed sore throat. The attack rate of sore throat was, respectively in the consumers and non-consumers, $68 \%$ and $44 \%$ $(p<0.01)$ for the beverage, and $78 \%$ and $37 \%$ $(p<0.001)$ for egg salad sandwich. However, there was no effect of beverage when it was assessed separately in those who ate or did not eat egg salad, indicating that the crude effect of beverage was in reality confounded by that of egg salad. ${ }^{3}$

These two examples illustrate the classic approach to investigating outbreaks of food borne disease, which consists in: (1) submitting a questionnaire to the people involved in an outbreak eliciting: (a) whether they ate or not the articles that were available, (b) whether they developed some form of illness; (2) use the data to compare the disease frequency (usually, attack rates) between consumers and non-consumers of those food items; (3) carry out stratified analyses if the crude analysis incriminates more than one article, to rule out confounding as the people who get sick are likely to differ from those who did not on the consumption of more than one food article. ${ }^{4}$ Alternatively, one may consider comparing those who develop the disease (cases) with those who did not (controls). This approach can be preferable if the group involved in the outbreak is not well enumerated and the investigation starts with a certain number of cases. ${ }^{5}{ }^{6}$ The crucial aspect is that some form of group comparison points to the solution to the problem.

But what is the origin of the methods of outbreak investigation used in the two examples? When were they first used? The elements comprising the now "classic approach" cannot have appeared all at once. We can see that there is some methodological progression between the Oswego County and the Miami jail investigations, in that the second disentangled the confounded effects of two food items. Concern 
over outbreaks of food borne disorders had become common in Europe and North America by the turn of the 20th century. There was a growing awareness that diseases like tuberculosis and trichinosis could be conveyed in animal foodstuffs, and the discovery by August Gaertner in 1885 of the bacillus now known as Salmonella enteritidis as the cause of an outbreak of food poisoning, brought a new awareness of gastroenteritis as a food borne disease. ${ }^{78}$ Health authorities began to record outbreaks: in Britain, for example, 14 outbreaks of food poisoning were noted between 1878 and 1896. By 1911, the count had risen to 79; in Germany some 85 outbreaks were recorded between 1880 and 1900. ${ }^{9}$ Such outbreaks provided numerous opportunities for public health officers to develop and refine their methodological approaches to these types of situations. We describe in this paper what may be one of the first reported experiences of using a menu questionnaire to investigate the causes of a disease outbreak. In 1902, H Timbrell Bulstrode, a British local government board inspector, investigated the origin of gastrointestinal disorders after banquets given at Winchester and Southampton. His work helped to confirm the role of oysters as an agent of transmission of typhoid fever. ${ }^{10}{ }^{11}$

\section{THE OUTBREAKS AT WINCHESTER AND SOUTHAMPTON}

As was customary in Britain at this period, banquets were held in towns across the country in the autumn of 1902 to celebrate the ending of the local mayor's term of office. In the old cathedral city of Winchester, in the south of England, the banquet took place on 10 November, at the city's guildhall. Of the 134 guests who attended, there were past and present members of the city council, former mayors, and local notables such as doctors, lawyers, businessmen, and members of the clergy. Those who lost their lives to typhoid after that evening's entertainment included Dr William England, consultant surgeon to the Royal Hampshire County Hospital, and the Rev William Stephens, Dean of Winchester. The prominence of this event in the annals of the local community meant that public alarm over the events that followed the dinner was severe, and the story was widely reported also in the national newspapers.

On 16 December 1902, Lockhart Stephens, the medical officer of health for Warblington District in Hampshire, informed the Local Government Board, England's central supervisory health authority, that several cases of enteric fever had occurred in the town of Emsworth and subsequently in Winchester and Southampton. There were reasons to suspect infected oysters to be responsible for the cases, but the role of oysters in enteric fever aetiology was not clearly established in England. The links between infected oysters and typhoid had received a great deal of publicity in the medical and lay press since the mid-1890s. ${ }^{12}$ While many doctors had been convinced of a causal connection, attempts to establish the link scientifically by means of the new techniques of bacteriology had had mixed results. Indeed, bacteriology was still a disputed science at this period, ${ }^{13}$ and the English fish trades had been combative in making use of scientific disagreements to contest claims of a causal connection between sewage contaminated shellfish and typhoid, as is evident in the pages of the trade journal, The Fish Trades Gazette. Moreover, many other foodstuffs were popularly associated with gastrointestinal disorders: at Winchester, for example, turtle soup and French beans featured along with the oysters as the popular suspects. It was against this background that the outbreaks at Winchester and Southampton assumed special significance in 1902. Because of Dr Stephens' information respecting Winchester and Southampton, and a communication from the Sanitary Committee of Portsmouth Corporation on
17 December in respect of typhoid cases in their own district, the Local Government Board instructed Dr $\mathrm{H}$ Timbrell Bulstrode to find out whether oysters were the culprit and rule out the role of other causes.

We first describe the investigation at Winchester, then reanalyse the data provided by Bulstrode, and finally discuss the strengths and weaknesses of Bulstrode's approach compared with modern theory of outbreak investigation.

\section{H TIMBRELL BULSTRODE'S REPORT ON THE MAYORAL BANQUET AT WINCHESTER}

The facts described by Bulstrode were alarming enough:

"Of these 134 guests, nine had, at the date of my visit on December $17^{\text {th }}$, developed enteric fever, as also had one of the waiters who officiated at the banquet, and who partook of a certain item in the menu. Of these 10 persons, two*, including the waiter were already dead ("Two more died subsequently, making four fatal cases in all.-H.T.B.). I gathered, too, from the Mayor and from members and officials of the Corporation who were present at the Guildhall at my preliminary conferences, that, in addition to the 10 cases of enteric fever, there had been, among persons present at the banquet, numerous cases of gastro-enteritis of varying degrees of severity." (page 129). ${ }^{15}$

The menu consisted of clear (turtle) and thick soups, fish and seafood (oysters; turbot and lobster sauce), smelts, meat, coldcuts and organs (boiled and roast mutton; roast beef; ham; tongue; kidneys and sweetbread); poultry (capons; turkey); game (venison, pheasants; partridge), vegetables (mushrooms and spinach), deserts (red currant jelly; Sir Watkin Wynn pudding; charlotte russe; liqueur jellies; caramel cream; maraschino cream; meringues; ice), cheese, salad, and aerated water. The two suspicious articles on the menu were the turtle soup (referred to as clear soup in the menu) and the oysters.

Bulstrode obtained a copy of the menu (reproduced in the appendix, available on line http://www.jech.com/ supplemental), which was sent to each of the guests, asking them to state which articles they had consumed, and

"... whether they suffered any indisposition or illness shortly after the banquet, and if so, the nature of such attack; and also whether they ascribed it to the banquet" (page 130). ${ }^{15}$

Bulstrode collected data on all the guests but essentially analysed the data obtained from those who became sick, that is, he computed the proportion of persons who had eaten a given food item among the 63 who became ill (all diagnoses) or among the 10 cases of enteric fever. There are several indications that Bulstrode was specifically interested in the cases and did not plan to directly compare those who became sick with those who did not: (1) he added to the nine cases diagnosed among the guests, one waiter who had died of enteric fever, but he did not incorporate the 42 other waiters and attendants in his analyses; (2) he never compared the prevalence of consumers in cases with that in people who did not get sick.

Bulstrode found that 2 of the 63 ill did not consume oysters and that all the cases of enteric fevers had eaten oysters. All other food items had not been taken by a substantial fraction of the sick or of those with enteric fever. It was clear, for example, that the turtle soup could not be involved as 23 of the sick and five of the enteric fever cases had not eaten it. 
Bulstrode could therefore rule out the allegation that the indisposition was attributable to the old copper vessel in which the soup had been prepared.

These results suggested to Bulstrode that the oysters were probably the culprits. He then confirmed his suspicion by gathering more evidence. Firstly, he collected "additional data" on 42 people, comprising waiters and other banquet attendants, who had not been included in the first survey. Of the 42 , eight ate oysters and none got enteric fever. Indeed, Bulstrode computed occurrence of enteric fever among the waiters and other banquet attendants: one case (the waiter included in the case series of table 1) of nine oyster eating waiters and other banquet attendants (eight "additional data" plus the dead waiter), and found it to be:

"about the same percentage incidence as upon oystereating guests, i.e., 9 cases among 113 oyster-eaters" (page 132) ${ }^{15}$

Bulstrode did not however compute the frequency of attacks for each specific food item. The data on the other banquet attendants are not included in the table given in the appendix of his paper.

Bulstrode also submitted the menu forms to the people who did not attend the full banquet. A few women apparently came at the end of the banquet and ate sandwiches, bread, butter, cakes, coffee, and strawberry ice cream. None became sick. Bulstrode also noted that the banquet

"was as far as could be ascertained, the only factor common to the lives of all those who were subsequently attacked" (page 133) 15
Bulstrode then compared the number of enteric fever cases among the banquet's participants $(\mathrm{n}=10)$ with the "prevalence of enteric fever in Winchester":

"It is of particular importance to ascertain how many persons there were suffering from enteric fever in Winchester at or about time of the banquet, but who were not present at such banquet. Dr Langdon has been good enough to furnish me with a list of the cases notified in Winchester during the last six months of 1902. From this list it appears that including the ten cases among persons who attended the banquet, there were only seven cases notified as enteric fever in Winchester since the end of June, and that of these seven cases four were in all probability imported, while one person was subsequently found not to have had enteric fever. Of these seven persons, therefore, probably only two contracted their disease in Winchester (page 133) 15

Bulstrode's full inspection included also: (1) the sanitary conditions of the houses affected by enteric fever; (2) the sources of milk supply to the 10 households in which enteric fever cases occurred; (3) the sanitary conditions of the Guildhall building; (4) the origin of the oysters consumed at the banquet, known in the trade as "Best French"; (5) a possible contamination of the oysters after they left the ponds. The last point was of particular relevance as a case of enteric fever had occurred in the caterer's family. But the case dated from August and September and could not be contagious by 1 November. Thus, it could not be causally related to the outbreak at Winchester.

There remained the enigma of the two guests who did not eat oysters but nevertheless fell sick. A closer examination of

Table 1 Comparisons of foods consumed at Winchester banquet between sick (any diagnosis, $n=63$; enteric fever, $n=10$ ) compared with not sick persons $(n=72)$. Source Bulstrode ${ }^{15}$

\begin{tabular}{|c|c|c|c|c|c|c|c|}
\hline \multirow{2}{*}{$\begin{array}{l}\text { Food served at Winchester } \\
\text { banquet* }^{*}\end{array}$} & \multicolumn{3}{|c|}{ Percentage who did eat (n)t } & \multicolumn{2}{|c|}{ Crude odds ratios (all illnesses) } & \multicolumn{2}{|c|}{ Crude odds ratios (enteric fever) } \\
\hline & All illnesses & Enteric fever & Not sick & OR & $(95 \% \mathrm{Cl})$ & OR & $(95 \% \mathrm{Cl})$ \\
\hline Oysters & $96.83(61)$ & $100.00(10)$ & $73.24(52)$ & 11.2 & $(2.5$ to 50.1$)$ & Infinity & Undefined \\
\hline Clear soup & 61.67 (37) & $37.50(3)$ & 55.07 (38) & 1.3 & $(0.6$ to 2.7$)$ & 0.5 & $(0.1$ to 2.2$)$ \\
\hline Thick soup & $32.20(19)$ & $42.86(3)$ & 27.94 (19) & 1.2 & $(0.6$ to 2.6$)$ & 1.9 & $(0.4$ to 9.5$)$ \\
\hline Smelts & $36.67(22)$ & 14.29 (1) & $42.03(29)$ & 0.8 & (0.4 to 1.6$)$ & 0.2 & $(0.0$ to 2.0$)$ \\
\hline Turbot and lobster sauce & 61.67 (37) & $71.43(5)$ & $46.15(30)$ & 1.9 & (0.9 to 3.8 ) & 2.9 & $(0.5$ to 16.1$)$ \\
\hline Sweetbread and spinach & $72.73(40)$ & $85.71(6)$ & $57.14(40)$ & 2.0 & (0.9 to 4.3 ) & 4.5 & $(0.5$ to 39.4$)$ \\
\hline Kidneys and mushrooms & $13.56(8)$ & 14.29 (1) & $21.13(15)$ & 0.6 & (0.2 to 1.5$)$ & 0.6 & $(0.1$ to 5.6$)$ \\
\hline Boiled mutton & $13.79(8)$ & $28.57(2)$ & $12.86(9)$ & 1.1 & $(0.4$ to 3.0$)$ & 2.7 & $(0.5$ to 16.1$)$ \\
\hline Roast mutton & $23.73(14)$ & $28.57(2)$ & $28.99(20)$ & 0.8 & (0.3 to 1.7 ) & 1.0 & $(0.2$ to 5.5$)$ \\
\hline Roast beef & $15.25(9)$ & $14.29(1)$ & $5.71(4)$ & 3.0 & $(0.9$ to 10.2$)$ & 2.8 & $(0.3$ to 28.7$)$ \\
\hline Venison & $38.33(23)$ & $28.57(2)$ & $32.39(23)$ & 1.3 & (0.6 to 2.7 ) & 0.8 & $(0.2$ to 4.6$)$ \\
\hline Red currant jelly & $26.67(16)$ & $28.57(2)$ & $31.88(22)$ & 0.8 & (0.4 to 1.7$)$ & 0.9 & (0.2 to 4.8$)$ \\
\hline Capons & $3.45(2)$ & 0 & $8.70(6)$ & 0.4 & $(0.1$ to 1.9$)$ & 0 & \\
\hline Ham & $12.28(7)$ & $14.29(1)$ & $21.54(14)$ & 0.5 & $(0.2$ to 1.4$)$ & 0.6 & $(0.1$ to 5.5$)$ \\
\hline Tongue & $8.47(5)$ & 0 & $5.88(4)$ & 1.5 & (0.4 to 5.8$)$ & 0 & \\
\hline Turkey & $24.56(14)$ & 0 & $31.43(22)$ & 0.7 & $(0.3$ to 1.6$)$ & 0 & \\
\hline Pheasant & $50.91(28)$ & $83.33(5)$ & $42.65(29)$ & 1.4 & (0.7 to 2.8$)$ & 6.7 & (0.7 to 60.7$)$ \\
\hline Partridge & $15.25(9)$ & $16.67(1)$ & $15.71(11)$ & 1.0 & $(0.4$ to 2.5$)$ & 1.1 & $(0.1$ to 10.1$)$ \\
\hline Sir Watkin Wynn pudding & $17.24(10)$ & $16.67(1)$ & $17.65(12)$ & 1.0 & $(0.4$ to 2.4$)$ & 0.9 & $(0.1$ to 8.7$)$ \\
\hline Charlotte russe & $10.34(6)$ & $28.57(2)$ & $9.09(6)$ & 1.2 & $(0.4$ to 3.8$)$ & 4.0 & $(0.6$ to 25.2$)$ \\
\hline Liqueur jellies & $20.69(12)$ & $12.5(1)$ & $18.18(12)$ & 1.2 & $(0.5$ to 2.9$)$ & 0.6 & $(0.1$ to 5.7$)$ \\
\hline Caramel cream & $8.47(5)$ & 0 & $10.77(7)$ & 0.8 & $(0.2$ to 2.6$)$ & 0 & \\
\hline Maraschino cream & $5.00(3)$ & 0 & $7.46(5)$ & 0.7 & $(0.1$ to 2.9$)$ & 0 & \\
\hline Meringue & $21.67(13)$ & $28.57(2)$ & 24.29 (17) & 0.9 & $(0.4$ to 2.0$)$ & 1.2 & $(0.2$ to 7.0$)$ \\
\hline Ice cream & $68.85(42)$ & $25.00(2)$ & $65.22(45)$ & 1.2 & $(0.6$ to 2.5$)$ & 0.2 & $(0.0$ to 0.9$)$ \\
\hline Cheese & $45.76(27)$ & $57.14(4)$ & $42.25(27)$ & 1.2 & $(0.6$ to 2.3$)$ & 1.8 & $(0.4$ to 8.8$)$ \\
\hline Salad & $23.33(14)$ & $28.57(2)$ & $23.19(16)$ & 1.0 & (0.4 to 2.3$)$ & 1.3 & $(0.2$ to 7.5$)$ \\
\hline Aerated water & $23.21(13)$ & $57.14(4)$ & $22.86(16)$ & 1.0 & $(0.4$ to 2.4$)$ & 4.5 & $(0.9$ to 22.2$)$ \\
\hline
\end{tabular}


their cases convinced Bulstrode that their disease was not attributable to oysters but probably to the "feast" in itself:

\begin{abstract}
"Mr. C. was quite well after the dinner on November 10" but on November $12^{\text {th }}$, and $13^{\text {th }}$ he suffered from abdominal pain. He had no nausea. For a fortnight prior to the banquet he had suffered from constipation, and shortly before the dinner he had taken an aperient. Mr. C. would not have attributed his illness to the banquet had there not been a rumour that several cases of illness had been caused by it.

Mr. F. was quite well until November $15^{\text {th }}$ [that is, 5 days after the banquet] when he suffered from a rigour, had a temperature of $102^{\circ}$, rapid pulse, furred tongue, and pain and tenderness in the hepatic regions, some vomiting. He had no diarrhea. His illness lasted about a week." (page $135)^{15}$
\end{abstract}

Bulstrode concluded that

"... the only item taken at the banquet capable of affording an adequate explanation of the attacks of illness which followed was the oysters. The fact that two of the guests who did not take oysters were attacked with illness after the banquet by no means suffices to negative the evidence tending to incriminate the oysters. As regards any feast of the magnitude of the Winchester banquet it might reasonably be expected that some of the guests would suffer indisposition afterwards; indeed, it may be regarded as probable that a few of those were ill, but who also took oysters, may in point of fact owe their illness to something other than the oysters." (pages 135-6) ${ }^{15}$

\section{REANALYSIS OF BULSTRODE'S DATA}

In the publication relating his investigation, Bulstrode published a table comprising all the data he had collected on 134 guests and one waiter-that is, 135 subjects. We have reanalysed the data as a case-control study using standard statistical software. We kept the two definitions of caseness used by Bulstrode. The first definition comprised all 62 subjects who got sick ("all illness"), whether they were diagnosed with enteric fever or not. The second case definition was restricted to the 10 cases of enteric fever (nine guests and one waiter). Controls comprised the 72 subjects who remained completely free of disease ("not sick").

Table 1 presents the results. The second and third columns give the percentages (and numbers) of all illness and of enteric fever cases that consumed specific food from the menu. The fourth column of table 1 shows data among controls, followed on the right by the odds ratios of the comparison of the controls (a) with all illness and (b) with the enteric fever only.

\section{Key points}

- H T Bulstrode has probably contributed to the development of the epidemiological way to investigate outbreak of food borne disease in being among the first- to the best of our historical knowledge - to use standardised menu forms.

- Since Bulstrode, methods for outbreak investigations have evolved and have in particular incorporated the systematic reliance on group comparisons.
The group comparison shows interesting features. Oysters had been notably popular. They were consumed by $97 \%$ of the sick and $73 \%$ of the non-sick. Those who got sick had consumed more "turbot and lobster sauce" and "sweetbread and spinach". On the other hand, mutton, roast beef, the dessert (except the ice cream), and the salad were not so attractive for the participants. The crude analysis yielded odds ratios close to unity with broad $95 \%$ confidence intervals (CI) for every food item but oysters, which stands out with the only strong and statistically significant odds ratio of $[(96.83 \div 3.17) \div(73.24 \div 26.76)=] 11.2(95 \%$ CI: 2.5 to 50.1$)$. Note that the variance of the odds ratio, which determines the confidence interval, has to be computed using the actual number of subjects rather than the percentages. There were no other statistically significant results for the foods listed with "all illness".

When limiting the diagnosis to enteric fever, the odds ratio for oysters was infinity (Fisher's exact $p$ value $=0.0503$ ). Cases also ate more pheasant and drank more aerated water but consumed less ice cream than the controls, but these three items were not associated with sickness in general. So that in this analysis too, the only item that comes out as a possible cause of the outbreak is the consumption of oysters.

\section{DISCUSSION}

This episode is informative on many aspects of the history of outbreak investigations. It shows how serious the risk of dying from a food borne infection was in 1902. Forty six per cent of the guests became sick. The incidence risk of typhoid fever was about $10 \%$ among the oyster eating people. But the case fatality rate was as high as $40 \%$ ( 4 deaths of 10 cases).

A modern analysis of Bulstrode's data fully confirms the original results obtained 102 years ago. The detail of the detective investigation aiming to prove beyond doubt that oysters were the culprits illustrates the creativity and imagination of public health inspectors around 1900.

Some mysteries remain. How did Bulstrode collect data on the two people who died from enteric fever before he started his inquiry? Perhaps he interrogated their dinner companions. In particular, having eaten oysters is the only information available on the diet of the waiter-case. Having eaten oysters but not turtle soup and some desserts is all that is known on the diet of another case.

Bulstrode used essential concepts of population thinking. He distinguished between prevalence of exposure and incidence of disease. He contrasted the number of cases that had occurred among the banquet's participants with the total number of cases diagnosed in the surrounding area. On the other hand, there is no indication that Bulstrode had considered the possibility of comparing exposed and unexposed to specific food items, or cases and controls, as we would have done today. Bulstrode did not compare the disease frequency in those who ate oysters and those who did not. Neither did he describe the experience of the people who did not get sick (controls), even though the data collected would have allowed him to do so.

The centre of Bulstrode's strategy was to identify all cases and then elicit symptoms and food consumed using a questionnaire. Cases were defined on the basis of their clinical symptoms, without reliance on bacteriology. The rationale was that articles eaten by only a small fraction of the cases could not have caused the disease. This rationale worked in the situation where a single article was involved. It may not have been that successful if several articles had been contaminated. We do not know if, had the problem been more complex, Bulstrode would have also relied on a more sophisticated analytical strategy.

Bulstrode's response to the problem at Winchester and Southampton was to devise the menu questionnaire. There is 
no evidence to suggest that it had been used before; he had not, for example, used it when inquiring into the puzzling incidence of typhoid in Chichester in 1896 (there was, however, no suggestion at the time that this was food related). ${ }^{16}$ It was not mentioned, and does not appear to have been used, in any of the food poisoning outbreaks reported to the Local Government Board in the 1880s. ${ }^{17}$ Nor was the technique used to investigate the outbreak among guests at three fraternity suppers at Wesleyan University Connecticut in 1894. There, the investigators (a biologist, a mathematician, and a geologist), using the bills of fare to trace the origins of every food item or drink, quickly identified oysters as the only plausible source of infection among the three articles common between the suppers. ${ }^{18}$ By 1902 the question of shellfish infection had become a matter of intense popular, trade, and scientific interest in England, and there can be little doubt that Bulstrode was determined on achieving certainty. ${ }^{19}$ While no specific comment as to the originality of his approach appears to exist, the Chief Medical Officer, William Power, noted:

"For the various steps by which this conclusion (that the oysters were blameworthyl was arrived at by the inspector, the student of "food poisoning" should refer to the report, which provides a model for procedure in future investigations of like sort" ${ }^{\prime \prime}$ (page 25) ${ }^{19}$

Bulstrode was a senior epidemiologist when he was appointed to solve the Winchester's tragedy. He had investigated several previous typhoid outbreaks for the Local Government Board, although this 1902 outbreak was the first of the board's typhoid inquiries to be specifically associated with a foodstuff other than milk. He was also the author of a report on the sanitary condition of English and Welsh shellfish laying, ${ }^{14}$ and he carried the flag for epidemiology as a competent independent medical science. As he noted in his report on the 1902 outbreak:

"No negative testimony, either bacteriological or chemical, would undo the fact that the oysters were laid down within a few yards of the main sewer. Moreover a positive result would in either case be superfluous ... I considered that if this outbreak ... had been caused by the ... oysters, the science of epidemiology should be competent to demonstrate the fact" (page 151) ${ }^{15}$

While the prominence of the victims in the local community may have added to Bulstrode's desire for scientific certainty in determining the cause of the outbreaks, the competing scientific authority of the different disciplines involved in public health at this period was perhaps a stronger motive for his innovative epidemiological method. Certainly, he used very similar approaches to both the Winchester and the Southampton outbreaks. The cases at Portsmouth, however, not being associated with a particular meal, were not deemed suitable for this treatment.

The events of November-December 1902 had their short term effect. In a sense, they marked the culmination of a process of growing unease over conditions in the shellfish trades, which had already seen failed attempts at regulation and legislation in the 1890s. There was enormous publicity in the popular and trade press. Early in 1903, well before Bulstrode's report had been published, the Worshipful Company of Fishmongers, which all but controlled the fish trades through its hold on the country's central fish market at Billingsgate, took steps to ensure that shellfish from polluted layings did not reach the markets. Indeed, they subsequently employed the eminent bacteriologist E E Klein to establish standards of bacteriological purity for shellfish. As a result of this particular scare, medical officers of health across Britain became more vigilant as regarded shellfish poisoning, the shellfish trades were obliged to accept supervisory regulation, and the public in general became charier of eating shellfish. ${ }^{12}$

It is difficult to assess with precision whether Bulstrode's report had an impact beyond that of the events themselves. The 1902 report, like most government reports, was published many months after it was completed. It ended with a note on the storage of oysters in shops, and a recommendation that they should be thoroughly cleaned before being placed in receptacles of "white impervious material" (page 153). ${ }^{15}$ The regulation of conditions in the retail shellfish trade continued, however, to depend on local circumstances as it did broadly across the British food industries in general. $^{8}{ }^{12}$

Evidence for subsequent use of the menu questionnaire by British practitioners so far uncovered is scanty. Much, however, may lie buried in the numerous records of local sanitary administrations. Two further significant outbreaks of gastroenteritis were associated with mayoral banquets at Wallasey and Portsmouth in 1924. Both were attributed to oysters. The medical officer for Wallasey simply reported that people at the banquet "replied to my queries" (page 36), ${ }^{20}$ but gave no details as to the form his queries took. His colleague at Portsmouth, A Mearns Fraser, a man with well established interests in epidemiology, did use the menu questionnaire, and detailed the results in his annual report. ${ }^{21}$ In both these investigations, however, the epidemiological evidence alone was not considered wholly sufficient of itself: the Chief Medical Officer pointed out that although it was strong, it had not been possible to obtain specimens for bacteriological examination, and other direct bacteriological evidence was not available. ${ }^{22}$

Thus, between 1904 and 1924, an important change had occurred in the scientific armament of health officers: bacteriology of shellfish had advanced sufficiently far to be considered a noteworthy contribution in examining the potential contamination of food items by pathogens. None the less, epidemiology did not become subordinated to bacteriology. ${ }^{23}$ Even today, laboratory investigations cannot entirely replace the role of the food menu approach in providing clues about which food items are infected.

\section{ACKNOWLEDGEMENTS}

We thank Professor Michael C Costanza and Mr Ba-Lau Luong for their help in analysing the data.

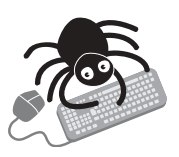

The letter and questionnaire used by Bulstrode is available on line (http://www/jech.com/ supplemental).

\section{Authors' affiliations}

A Morabia, Division of Clinical Epidemiology, Geneva University Hospitals, Geneva, Switzerland

A Hardy, The Wellcome Trust Centre for the History of Medicine at University College London, UK

Funding: none

Conflicts of interest: none declared.

\section{REFERENCES}

1 Gross M. Oswego County revisited. Public Health Rep 1976;91:168-70.

2 Gordis L. Epidemiology. 2nd ed. Philadelphia: Saunders, 2000.

3 Centers for Disease Control. Outbreak of foodborne streptococcal diseaseFlorida. MMWR 1974;23:365-6.

4 Helstad AG, Mandel AD, Evans AS. Thermostable Clostridium perfringens as cause of food poisoning outbreak. Public Health Rep 1967;82:157-61. 
5 Kelsey JL, Thompson WD, Evans A. Methods in observational epidemiology New York: Oxford University Press, 1986.

6 Centers for Disease Control. Legionnaires's disease outbreak associated with a grocery store mist machine-Lovisiana, 1989. MMWR 1990;39:108-9.

7 Zylberman P. Making food safety an issue: internationalized food politics and French public health from the 1870s to the present. Med Hist 2004;48:1-28.

8 Hardy A. Food, hygiene, and the laboratory. A short history of food poisoning in Britain, circa 1850-1950. Soc Hist Med 1999;12:293-311.

9 Savage W. Bacterial food poisoning and food infections. Rep Public Health Med Subjects 1913;77:1-70.

10 Hardy A. On the cusp: epidemiology and bacteriology at the local government board, 1890-1905. Med Hist 1998;42:328-46.

11 Hardy A. Methods of outbreak investigation in the "era of bacteriology" 1880-1920. Soz Praventivmed 2001;46:355-60.

12 Hardy A. Exorcizing Molly Malone: typhoid and shellfish consumption in urban Britain 1860-1960. History Workshop Journal 2003;55:73-90.

13 Hamlin C. A science of impurity. Water analysis in nineteenth century Britain Bristol: Adam Hilger, 1990.

14 Bulstrode HT. The prevalence of enteric fever in the city of Chichester. MOAR Local Government Board British Parliamentary Papers 1897;37:137-64.

15 Bulstrode HT. Report upon alleged oyster-borne enteric fever and other illness following the Mayoral Banquets at WInchester and Southampton, and upon enteric fever occurring simultaneously elsewhere, and also ascribed to oysters. Medical officer's annual report. Local Government Board British

Parliamentary Papers 1902;26:129-79.

16 Bulstrode HT. The prevalence of enteric fever in the city of Chichester. Medical officer's annual report. Local Government Board British Parliamentary Papers 1897;37:137-64.

17 Ballard E. Summary review of 14 instances [of food poisoning] reported upon since 1879. Medical officer's annual report. Local Government Board British Parliamentary Papers 1890;34:245-58.

18 Conn H. Copy of a report on the outbreak of typhoid fever at Wesleyan University. MOAR Local Government Board British Parliamentary Papers 1896;37:274-89

19 Power W. Annual report. Medical officer's annual report. Local Government Board British Parliamentary Papers 1904;26:1-698.

20 Barlow TWN. Medical officer's annual report. Wallasey: Wallasey County Borough, 1924

21 Mearns Fraser A. Medical officer's annual report. Portsmouth: City Council, 1924.

22 Newman G. Chief medical officer's annual report. London: Ministry of Health, 1924.

23 Morabia A. Epidemiology and bacteriology in 1900: who is the handmaid of whom? J Epidemiol Community Health 1998;52:617-18. 